\title{
Impact of raindrop sizes and intensities on the microcharacteristics of soil aggregates
}

\author{
Mingxi Yang ${ }^{1}$, Gangan $\mathrm{Ma}^{2}$, guangluli $\mathrm{li}^{3}$, Yangyang $\mathrm{Ren}^{4}$, and Zefang $\mathrm{Li}^{4}$ \\ ${ }^{1}$ Northwest Agriculture and Forestry University \\ ${ }^{2}$ Northwest Agriculture and Forestry University College of Resources and Environment \\ ${ }^{3}$ northwest A \& F University \\ ${ }^{4}$ Northwest A\&F University
}

July 16, 2020

\begin{abstract}
Aggregate breakdown caused by the impact of raindrops clogs soil pores, reduces soil infiltration and aggravates the formation of soil crusts. To determine the influence of raindrop splash on the microstructure of soil aggregates, the typical loess was studied. We used synchrotron-based X-ray microcomputed tomography (SR- $\mu \mathrm{CT}$ ) to analyze the microcharacteristics of soils impacted by rainfall intensities. The results showed that raindrop splash increases the number of surface soil aggregates, especially when the rainfall intensity is 68.61 or $217.26 \mathrm{~mm} \mathrm{~h}-1$. Compared to the undisturbed soil, the number of soil aggregates increased by $38.71 \%, 46.77 \%$ and $76.77 \%$, and the volume increased by $1.09 \%, 3.21 \%$ and $3.73 \%$, after the impact of rainfall intensities of 5.76, 68.61 and $217.26 \mathrm{~mm} * \mathrm{~h}-1$, respectively. Raindrop impact on the surface affects the distribution of aggregate particles, causing a decrease in the number of aggregate particles in the 500-1000 $\mu \mathrm{m}$ range and an increase in the $<500 \mu \mathrm{m}$ range. Compared with unsplashed soil, there is a significant increase in the fractal dimension (FD) and total specific surface area (SSA) of surface soil aggregates in splashed soil. Particularly, the rainfall intensity of $217.26 \mathrm{~mm}$ h- 1 resulted in an increase of the FD and SSA by $30.24 \%$ and $17.49 \%$, respectively. Under the rainfall intensities, the average particle diameter of the soil aggregates decreased by $2.43 \%, 3.25 \%$ and $3.55 \%$, respectively, compared with that of the undisturbed soil. These results indicated that raindrop splash decreased the number of macroaggregates and increased the number of microaggregates in the surface layer of soil.
\end{abstract}

\section{INTRODUCTION}

Soil aggregates are the basic units of structure in soil. The breakdown and dispersion of soil aggregates caused by raindrop splashing, initiate soil erosion (Bronick and Lal, 2005; Legout et al., 2005; Xiao et al., 2017). Soil aggregate stability plays a key role in affecting surface runoff and soil erosion; furthermore, it has been widely used to evaluate soil structural stability and soil quality (Six et al., 2000; Ghadir et al., 2007; Anderson et al., 2019). Numerous studies have been conducted on aggregates in soil erosion (Fu et al., 2017, 2019), and these studies mostly analyzed the particle size distribution of split aggregates after rainfall. During a rainfall event, the fragmentation and separation of aggregates was mainly caused by large-diameter raindrops; as the raindrop diameter increased, the degree of fragmentation in the aggregates became stronger (Fu et al., 2017; Li et al., 2018). Additionally, Fu et al. (2019) used a simulated rainfall test to analyze the extent of soil splash erosion and the distribution of particle sizes and determined the effects of different rainfall energy levels on the breakdown of soil aggregates. Furthermore, Fu et al. (2020) assessed the effects of secondary raindrop splash erosion on aggregate fragmentation and fragment size distribution and found that secondary raindrop splash erosion would cause soil aggregates to break again, leading to a reduction in soil fertility and productivity. Obviously, previous studies have ignored the impacts of raindrop splash on the microstructure of aggregates. 
In recent years, the development of X-ray computer scanning (CT) technology has allowed for its application in the study of soil structure and soil aggregates (Peth et al., 2008; Munkholm et al., 2012; Garbout et al., 2013; Gao et al., 2019). Through synchrotron-based X-ray microcomputed tomography (SR- $\mu$ CT) scanning, high-resolution images of soil can be obtained, and three-dimensional qualitative and quantitative analysis of soil aggregates can be performed, thereby analyzing the internal microstructure of aggregates in a nondestructive and comprehensive manner (Taina et al., 2008; Ma et al., 2015; Han et al., 2019). Some research has utilized CT scanning technology to quantify the effects of different land use types, fertilization conditions, and types of vegetation restoration and succession on soil pore structure and aggregates (Luo et al., 2010; Zhou et al., 2012; Dal Ferro et al., 2013; Zhao et al., 2017). Hu et al. (2016) and Li et al. (2019) applied CT scanning technology to analyze soil macropores and root structure from alpine vegetation and different ecosystems in the Qinghai Lake Basin of China in an effort to explore the impact of roots on soil macropore network characteristics. In addition, work from Ma et al. (2015) based on SR- $\mu$ CT scanning technology investigated the influences of pore characteristics on water stability and the tensile strength of aggregates under wetting and drying cycles. Additional research has used high-resolution CT to characterize the development of crust over time, and the results showed that the cumulative porosity varied according to soil depth (Lee et al., 2008). With the help of simulation rainfall experiments and SR- $\mu$ CT scanning, Li et al. (2018) analyzed the effects of raindrop splashing on the fragmentation mechanism of aggregate microstructure from a two-dimensional perspective.

As we all know, the Loess Plateau is a region among those with the most serious soil erosion in the world, and one of its main causes of erosion is water erosion. The fragmentation and dispersion of topsoil aggregates caused by raindrops is the first step of soil erosion, but it is unclear how rainfall causes microstructural changes in soil aggregates. Although SR- $\mu$ CT scanning has been widely used in soil research, this does not hold true in the field of soil erosion; to date, CT scanning has rarely been employed to analyze the impact of rainfall on the microstructure of aggregates. However, the microstructure of soil aggregates determines the soil stability and quality characteristics (Zhou et al., 2012). Therefore, utilizing SR- $\mu$ CT and image analysis, the aims of this research were (1) to compare the differences in the three-dimensional microstructure of soil aggregates under raindrops and (2) to analyze the relationship between the rainfall intensity and microscopic characteristics of the soil aggregates. The results presented here may be beneficial by revealing the mechanisms of aggregate fragmentation, pore clogging and the formation of a surface crust during soil erosion.

\section{MARERIALS AND METHODS}

\subsection{Soil samples}

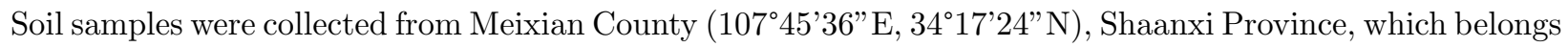
to a warm and subhumid continental climate. The average annual precipitation is $610 \mathrm{~mm}$, occurring mainly from July to September, with an average annual temperature of 12.9. The study area was a traditional agricultural cropland region located in the southern section of the Loess Plateau in China. The soil was formed from loess parent material (according to the USDA particle size classification criteria) (Fu et al., 2017). The diagonal method was used to collect 30 undisturbed soil samples from the surface $(0-5 \mathrm{~cm}$ depth) with a ring knife $\left(10 \mathrm{~cm}\right.$ diameter $\mathrm{x} 5 \mathrm{~cm}$ height). Bulk density $\left(1.29+-0.07 \mathrm{~g} \mathrm{~cm}^{-3}\right)$ was determined with oven drying at $105 \mathrm{deg} \mathrm{C}$ until a constant mass was obtained. The soil organic matter content $(1.33 \%+-$ $0.04)$ was measured by the combustion method. The pipette method was used to obtain the particle size distribution (sand $(0.02-2 \mathrm{~mm}) 45.96 \%+-0.12 \%$, silt $(0.002-0.02 \mathrm{~mm}) 41.06 \%+-0.03 \%$, clay $(<0.002 \mathrm{~mm})$ $12.98 \%+-0.05 \%)$.

\subsection{Rainfall test}

The simulated rainfall device was composed of a raindrop generator and a splashing raindrop collection device (Figure 1) (Fu et al., 2017). The raindrop generator was a cylinder $(10 \mathrm{~cm}$ in diameter and $10 \mathrm{~cm}$ in height) with a top opening, 21 syringe needles were installed at the bottom of the cylinder, and raindrops of different diameters were generated by changing the needle size. The collection device for splashed raindrops was a stainless-steel pan (110 cm in diameter). To prevent the raindrops from being disturbed by the horizontal 
airflow, a shield was placed around the experimental device. The duration for testing each raindrop diameter was 10 minutes, and each diameter test was repeated 3 times.

Three rainfall intensity levels $\left(5.76,68.61\right.$, and $\left.217.26 \mathrm{~mm} \mathrm{~h}^{-1}\right)$ determined by three raindrop diameters were selected in the experiment. The corresponding raindrop diameters were $2.67 \mathrm{~mm}, 3.39 \mathrm{~mm}$ and 4.05 $\mathrm{mm}$, respectively. The rainfall intensity was measured by the direct method. For all needles of each size, continuous rainfall was performed for 10 minutes, and the precipitation volume was determined. The rainfall intensity was calculated according to the rainfall area and rainfall time. Each test was conducted 10 times, the maximum and minimum values were removed, and the average of the remaining 8 replicates was calculated to be the rainfall intensity. When the raindrop diameter was greater than or equal to $1.9 \mathrm{~mm}$, the modified Newton formula (equation [1]) was used to calculate the final velocity of the raindrops. The raindrop velocity under this test condition was calculated using equation [2]. The raindrop energy was calculated by equation [3].

$d>1.9(1)$

where $\mathrm{V}_{\mathrm{i}}$ is the terminal velocity $\left(\mathrm{m} \mathrm{s}^{-1}\right)$, $\mathrm{d}$ is the raindrop diameter $(\mathrm{mm}), \mathrm{V}$ is the raindrop velocity $(\mathrm{m}$ $\left.\mathrm{s}^{-1}\right)$, $\mathrm{g}$ is the acceleration of gravity $\left(\mathrm{m} \mathrm{s}^{-2}\right), \mathrm{H}$ is the height from which the raindrop falls $(\mathrm{m}), \mathrm{E}_{\mathrm{rs}}$ is the raindrop energy $\left(\mathrm{J} \mathrm{m}^{-2} \mathrm{~s}^{-1}\right), \mathrm{n}$ is the number of raindrops, $\mathrm{i}=0, \ldots$, and $\mathrm{m}$ is the individual raindrop mass (g). The main parameters of the simulated raindrops are shown in Table 1.

After the rainfall test, the soil in the cutting ring was air dried naturally. Dry clods $(2 \mathrm{~cm}$ cubes) from the surface of the impacted soil (a depth of approximately $0.5 \mathrm{~cm}$ ) were obtained by using a knife before and after each rainfall event. The soil clods were placed in a container with a sponge to keep the structure intact. A total of 54 dry clods were selected for CT scanning.

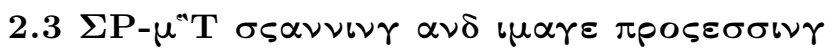

The soil clods ( $5 \mathrm{~mm}$ in diameter) were scanned using synchrotron-based X-ray microcomputed tomography $(\mathrm{SR}-\mu \mathrm{CT})$ at beamline BL13W1 in Shanghai, China. The scan was performed at an energy level of $24 \mathrm{kV}$, with an exposure time of $1.8 \mathrm{~s}$, a detection distance of $11 \mathrm{~cm}$, and a resolution of $3.25 \mu \mathrm{m}$. The sample stage rotates at a constant speed from 0 to $360^{\circ}$, and the scan is continuously performed at a scan interval of 0.625 $\mathrm{mm} ; 720$ original images (tomo images) were obtained for each soil sample. Then, PITRE (Phase-sensitive X-ray Image Processing and Tomography Reconstruction) software was used for phase retrieval and slice reconstruction based on the back-projection algorithm (Chen et al., 2012). A total of 1500-2000 slice images $(2048 \times 2048$ pixels $)$ were obtained for each soil clod and stored as 32-bit grayscale images in tiff format.

The open-source software ImagePy was used to complete image processing, visualization and quantification of the three-dimensional aggregate structure (Wang et al., 2018). To avoid the influences of soil depth and image boundary, a total of 512 images with serial numbers 512-1024 were selected, and a nonedge section of $512 \times 512 \times 512$ pixels (i.e., $1.664 \mathrm{~mm} \times 1.664 \mathrm{~mm} \times 1.664 \mathrm{~mm}$ ) in size was selected as the target area for image analysis. The process of dividing the grayscale image into the soil matrix and pores by thresholding, which is called binary segmentation, was key to the quantitative analysis of soil structure. This study used the automatic Otsu algorithm of the global threshold method (Zhou et al., 2012; Garbout et al., 2013) to perform binary segmentation which was subsequently completed by visual observation and manual adjustment. After image binarization, the three-dimensional visualization function of the ImagePy software was used to visualize the three-dimensional structure of soil aggregates (Wang et al., 2018) (Figure 2).

\subsection{Calculation and analysis}

ImagePy software (Wang et al., 2018) was used to analyze the segmented binary image and obtain the quantity, diameter, surface area and volume of soil aggregate particles; subsequently, the 3D structural characteristics of the aggregate after splashing with different raindrop sizes were obtained through calculation 
and analysis. Aggregate fragments were divided into six classes according to their size: 500-1000, 250-500, 106-250, 53-106, 25-53 and $<25 \mu \mathrm{m}$.

The quantity and volume parameters of soil aggregates were used to measure the quantitative characteristics of aggregates. The three-dimensional mass fractal dimension (FD) and specific surface area (SSA) of each aggregate were used to characterize the extent of aggregate fragmentation. The FD and SSA are parameters that can appropriately reflect the geometry of soil structure. They represented the size of aggregates, soil erosion resistance and soil permeability (Pirmoradian et al., 2005; Wang et al., 2014). The FD was previously used to describe the self-similarity and scale independence of objects (Dal Ferro et al., 2013). The calculation of FD was based on the principle of the box counting method: the image stack was covered with cube boxes of different side lengths, and the number of boxes was recorded (Kravchenko et al., 2011; Perret et al., 2003) to satisfy the following relationship (equation [4]):

\section{(4)}

where $\mathrm{N}(\varepsilon)$ is the number of boxes, $\varepsilon$ is the side length of the box, FD is the value of fractal dimension.

FD was calculated by linear regression of $\log \{\mathrm{N}(\varepsilon)\}$ vs $\log (1 / \varepsilon)$, and the range was 2-3. Fractal dimension was computed using the open-source software ImagePy (Wang et al., 2018). Specific surface area is volumespecific surface area, expressed as the ratio of surface area to volume of each aggregate fragment.

The data was analyzed using one-way analysis of variance (ANOVA). Duncan's multiple range method was used to compare mean values, and significant differences between mean values were defined as $P<0.05$. The results were expressed as the mean standard deviation, and all tables and figures were processed in Microsoft Office Excel 2010.

\section{RESULTS}

\subsection{Soil aggregatequantitative characteristics}

Raindrop splashing increased significantly with rainfall intensity $(P<0.05$, Table 2$)$ and resulted in an increase in the number of soil aggregate fragments. Compared to the undisturbed soil, the total number of soil aggregate particles increased by $38.71 \%, 46.77 \%$ and $76.77 \%$ after the impacts of rainfall intensities of $5.76,68.61$ and $217.26 \mathrm{~mm} \mathrm{~h}^{-1}$, respectively (Table 2). Overall, the number of soil aggregate particles in the undisturbed and disturbed soil showed an "increasing-decreasing-increasing" trend as the aggregate particle size decreased (Fig. 3A). Following raindrop splashing, the number of aggregate particles with different sizes (except for larger aggregates of 500-1000 $\mu \mathrm{m}$ ) was higher than that in the undisturbed soil. After raindrop splashing, the quantity of soil aggregate fragments between $250-500 \mu \mathrm{m}$ increased by $34.88 \%, 27.91 \%$ and $44.19 \%$, respectively, compared to the undisturbed soil $(P<0.05$, Figure $3 \mathrm{~A})$. After splashing with a rainfall intensity of $217.26 \mathrm{~mm} \mathrm{~h}^{-1}$, the largest quantity of aggregate particles existed in the 106-250 $\mu \mathrm{m}$ range, accounting for $53.36 \%$ of the total amount; this value was significantly increased by $98.65 \%$ compared to that of the undisturbed soil $(P<0.05$, Figure $3 \mathrm{~A})$.

With the increase in rainfall intensity, the total volume of aggregate fragments raised gradually (Table 2). Compared to the undisturbed soil, the difference was not significant after the impact with a rainfall intensity of $5.76 \mathrm{~mm} \mathrm{~h}^{-1}\left(P>0.05\right.$, Table 2). Following impact with rainfall intensities of 68.61 and $217.26 \mathrm{~mm} \mathrm{~h}^{-1}$, the total volume of aggregate fragments increased $3.21 \%$ and $3.73 \%$, respectively, $(P<0.05$, Table 2$)$. The percentage of aggregate volume (\%) was the ratio of the aggregate volume of a particles size aggregate to the total aggregate volume in a soil clod, which reflected the distribution of aggregate fragments in the soil. The percentage of aggregate volume under different treatments showed a trend of increasing first and then decreasing with the decrease of particle size, and reached the maximum at 500-250 $\mu \mathrm{m}$. Compared to the disturbed soil, the aggregate in 500-250 $\mu \mathrm{m}$ of the disturbed soil impacted by $5.76,68.61$ and $217.26 \mathrm{~mm} \cdot \mathrm{h}^{-1}$ rainfall intensity were significantly $(P<0.05)$ increased by $39.49 \%, 25.41 \%$ and $24.76 \%$, respectively (Fig. 3B). The percentage of aggregate fragments that were $>500 \mu \mathrm{m}$ in disturbed soil was lower than that of undisturbed soil $(P<0.05)$, while it was higher for fragments $<500 \mu \mathrm{m}$ than that of undisturbed (Figure 
3B). In addition, for fragments $>106 \mu \mathrm{m}$, the volume of soil aggregate particles accounts for more than $99.00 \%$ of the total aggregate volume (Figure $3 \mathrm{~B}$ ).

\subsection{Soil aggregate fragments characteristic parameters}

As shown in Fig. 4A, the fractal dimension of the soil aggregates increased significantly in comparison with the undisturbed soil following different rainfall conditions $(\mathrm{P}<0.05)$. After being splashed by rainfall with an intensity of 5.76 or $68.61 \mathrm{~mm} \mathrm{~h}^{-1}$, the fractal dimension of the soil aggregates had no significant change $(\mathrm{P}>$ 0.05). After being splashed by rainfall at an intensity of $217.26 \mathrm{~mm} \mathrm{~h}^{-1}$, the fractal dimension was significantly higher than that of the other treatments $(\mathrm{P}<0.05)$. After being splashed by three rainfall intensities, the fractal dimension of the aggregates increased by $2.26 \%, 2.26 \%$ and $3.67 \%$ respectively, compared to that of the undisturbed soil.

After raindrop splash, the total specific surface area of the soil aggregates increased significantly $(\mathrm{P}<0.05$, Fig. 4B). The total specific surface area of the splashed soil was significantly different from that of the unsplashed soil $(\mathrm{P}<0.05)$, but there was no difference between the rainfall intensities of 5.76 and $68.61 \mathrm{~mm}$ $\mathrm{h}^{-1}(\mathrm{P}>0.05$, Fig. 4B). The total specific surface areas of the soil aggregates splashed by rainfall intensities of $5.76,68.61$ and $217.26 \mathrm{~mm} \mathrm{~h}^{-1}$ increased by $18.82 \%, 17.79 \%$ and $30.24 \%$ respectively (Figure $4 \mathrm{~B}$ ).

The specific surface area of the soil aggregate increased with decreasing aggregate particle size, especially for the $<25 \mu \mathrm{m}$ aggregates (Figure 4C). For the 500-1000 $\mu \mathrm{m}$ aggregates, the specific surface area of soil splashed with raindrops was significantly higher than that of the unsplashed soil $(\mathrm{P}<0.05)$, but there was no significant difference between the different rainfall intensities $(\mathrm{P}>0.05$, Fig. $4 \mathrm{C})$. After raindrop splash, the specific surface areas of the 250-500 $\mu \mathrm{m}$ aggregates were higher than those of the undisturbed soil, whereas the specific surface areas of the 106-250 $\mu \mathrm{m}$ and 53-106 $\mu \mathrm{m}$ aggregates fluctuated. After being splashed by rainfall at an intensity of 68.61 and $217.26 \mathrm{~mm} \mathrm{~h}^{-1}$, the specific surface area of the $25-53 \mu \mathrm{m}$ aggregates was significantly different from that of the undisturbed soil, increasing by $31.99 \%$ and $102.50 \%(\mathrm{P}<0.05)$, respectively, and the SSA was significantly higher than that of other rainfall intensities $(\mathrm{P}<0.05)$. The specific surface areas of aggregates in the undisturbed soil and splashed soil had a maximum value in the $<25$ $\mu \mathrm{m}$ range; the specific surface areas of soil splashed by small, medium and large rainfall intensities increased by $9.15 \%, 10.92 \%$ and $17.49 \%$, respectively, compared with undisturbed soil.

\subsection{Microstructures of soil aggregates}

A significant difference was observed in the two-dimensional shape between the splashed soil aggregates and the undisturbed soil (Figure 2D). The undisturbed soil aggregates primarily consisted of macroaggregates with clear outlines and boundaries, containing more macropores and a relatively loose soil structure (Figure 2A). Compared with the undisturbed soil, the soil structure after raindrop splashing was more compact, the number of macropores was reduced, the number of small and medium aggregates was increased, and the phenomenon of fragmentation was shown. Markedly, after being splashed by rainfall at the intensity of $217.26 \mathrm{~mm} \mathrm{~h}^{-1}$, the soil aggregates were the most broken (Figure 2B-D). The 3D structural differences of soil aggregates were more obvious than those in 2D (Figure 2 and 3D). After splashing, the percentage of soil macroaggregates was reduced, being replaced by an increased number of microaggregates; this result indicates that the aggregates were obviously broken, and the soil structure was relatively denser. Table 3 reports that the average aggregate particle size in splashed soil was significantly smaller than that of the undisturbed soil $(\mathrm{P}<0.05)$, especially after a rainfall intensity of 68.61 and $217.26 \mathrm{~mm} \mathrm{~h}^{-1}$. The average aggregate particle size decreased by $2.43 \%, 3.25 \%$ and $3.55 \%$ after splashed by three rainfall intensities, respectively. This result is consistent with the micromorphology of aggregates.

\section{DISCUSSION}

\subsection{Effect of rainfall intensity on splashed soil aggregates quantitative characteristics}

The number of aggregate fragments increased corresponding to the increase in rainfall intensity, especially at 68.61 and $217.26 \mathrm{~mm} \mathrm{~h}^{-1}$ (Table 1). In the process of water erosion, the primary mechanisms of aggregate breakdown are fast wetting and mechanical breakdown caused by raindrop impact (Legout et al., 2005; Shi 
et al., 2010). The results here show that, with an increase of rainfall intensity, the quantity of aggregates and the degree of fragmentation gradually increase.

In regards to aggregate distribution, aggregates mainly consisted of 250-500 $\mu \mathrm{m}, 106-250 \mu \mathrm{m}$, and $<25 \mu \mathrm{m}$ particle sizes, whereas for volume, the 106-1000 $\mu \mathrm{m}$ range made up the majority (Fig. 3A and 3B). Raindrop impact on the surface could affect soil erosion and alter aggregate structure in various ways (Kinnell et al., 2005). When the erosion process was dominated by rainfall detachment, the particle size distribution of eroded soil was different from that of the original soil (Slattery and Burt, 1997). It was affected by the particle distribution of the original soil and the destruction of aggregates during erosion (Mahmoodabadi et al., 2014). Based on the number and volume of aggregate fragments, we found that raindrop splashing dispersed larger aggregate particles $(500-1000 \mu \mathrm{m})$ and broke them into aggregates of smaller particles $(<500 \mu \mathrm{m})$. Raindrop splashing changed the arrangement of soil particles, decreased the number of larger aggregate particles, and increased the quantity of smaller aggregate particles. As a result, the particles formed by dispersion and fragmentation were deposited in the pores of the upper soil, clogging the pores of the topsoil and forming a thin, dense surface crust with low permeability (Assouline, 2004). In turn, the crust further reduced soil infiltration and exacerbated soil erosion (Sajjadi and Mahmoodabadi, 2015).

\subsection{Effect of rainfall intensity on splashed soil aggregate fragment parameters}

The impact of raindrops increased the FD of the soil aggregates (Figure 4A). A greater FD value corresponded to a greater degree of aggregate breakdown and detachment. The FD ratios of the aggregates splashed by rainfall intensities of 5.76 and $68.61 \mathrm{~mm} \mathrm{~h}^{-1}$ were higher than those of the aggregates splashed by a rainfall intensity of $217.26 \mathrm{~mm} \mathrm{~h}^{-1}$ because the higher rainfall intensity had higher energy, which strengthened the degree of fragmentation and caused more macroaggregates to decompose into microaggregates. The higher FD value indicates that the particle size distribution of aggregates is dominated by smaller particles, a lower proportion of stable aggregates is present, and the soil structure is inferior (Tyle et al., 1992, Huang et al., 2017). The results presented here show that the raindrop splash was able to break apart the aggregate and destroy the surface soil structure. This is consistent with the result of Fu et al. (2020).

Soil aggregate index, such as specific surface area (SSA), can also reflect the stability of soil aggregates (Pirmoradian et al., 2005). Raindrop splash led to an increase in the total specific surface area of soil aggregates, which increased as the intensity of rainfall increased (Figure 4B). As the particle size decreased, the corresponding specific surface area increased (Figure 4C). This result has proven that a higher specific surface area, leads to a finer soil texture and a stronger soil dispersibility (fragmentation) (Wang et al., 2014). The specific surface area of the aggregates increased significantly, especially in the $25-53 \mu \mathrm{m}$ and $<25 \mu \mathrm{m}$ aggregate particles, after being splashed by 68.61 and $217.26 \mathrm{~mm} \mathrm{~h}^{-1}$ (Figure $4 \mathrm{~B}$ and $4 \mathrm{C}$ ). This likely occurred because large raindrops had a stronger rainfall intensity and rainfall energy, thus, increasing the rainfall intensity strengthened the aggregate decomposition (Sajjadi and Mahmoodabadi, 2015). Therefore, the splashed soil aggregates contained more fine particles than before the splash (Figure 4C). Meanwhile, as the particle size of aggregates decreased, they exhibited a smaller mass and smoother shape; furthermore, migration and denudation were more likely to occur during runoff transportation and the underlying pores were more likely to be clogged (Assouline et al., 2004), causing compaction of the aggregate microstructures (Adesodun et al., 2007; Li et al., 2018). In addition, some studies have shown that a greater amount of organic matter content was present in surface soil macroaggregates (Jastrow, 1996) and that aggregates have physical protection for organic matter (Field et al., 2006), while the total specific surface area was negatively correlated with organic matter content. Compared with soil containing higher organic matter content, soil with lower organic matter content showed higher sealing and anti-crust properties (Ramos et al., 2003). Therefore, the aggregate breakdown caused by raindrop splash decreased the soil structure and fertility, reduced the land productivity, and even aggravated the formation of crust (Hu et al., 2018; Fu et al., 2020).

\subsection{Effect of raindrop diameters on microscopic characteristics splashed soil aggregates}

The microstructure of soil aggregates was different in two and three dimensions after raindrop splash (Figure 
2). The splashed soil, especially by large raindrops, displayed an obvious fragmentation of aggregates (Figure $2 \mathrm{D})$. This result indicated that the main cause of aggregate fragmentation was large raindrops. It is easier to form a structure consisting of large aggregates after drying. The formation of surface crust depended on the degree of surface aggregate fragmentation and the stability of the soil structure (Wick et al., 2016; Gelaw et al., 2015). The splashed soil aggregate particle size was smaller than that of the undisturbed soil (Table 2). This result is consistent with that of Ramos et al. (2003), in which the fragmentation of aggregates produced smaller particles than the original soil, allowing the soil to be displaced and reoriented into a more continuous structure; this consequently clogged pores and formed a surface crust. Sajjadi and Mahmoodabadi (2015) found that soil containing finer particle aggregates had a higher transportability of preseparated particles than larger aggregates. Moreover, as particle size decreased and the texture became finer, the pore structure of the soil became denser. The impact of raindrops, which caused physicochemical compaction and dispersion of the surface soil, was the main reason for crust formation and reduction of the infiltration rate (Assouline et al., 2004; Fu et al., 2017). In this study, larger raindrop diameters resulted in greater corresponding rainfall intensity and energy. As a result, soil tends to form a surface crust after heavy rains. The formation of a soil surface crust not only further reduces porosity (Pagliai et al.,2004) but also reduces surface roughness, thereby exacerbating surface runoff and soil loss (Robinson and Phillips, 2001; Assouline and Ben-Hur, 2006).

\section{CONCLUSIONS}

This study found that the number of aggregates increased as the rainfall intensity increased, especially for the rainfall intensities of 68.61 and $217.26 \mathrm{~mm} \mathrm{~h}^{-1}(P<0.05)$. The distribution of aggregate particles was affected by the original soil distribution and rainfall intensity, which decreased the number of 500-1000 $\mu \mathrm{m}$ aggregate particles and increased the number of $<500 \mu \mathrm{m}$ aggregate particles. The fractal dimension (FD) and specific surface area (SSA) increased significantly after raindrop splash $(P<0.05)$; as rainfall intensity increased, the FD and SSA values also increased. A greater degree of fragmentation led to a higher proportion of fine particles in the soil and more unstable soil aggregates. After raindrop splashing, especially from an intensity of 68.61 and $217.26 \mathrm{~mm} \mathrm{~h}^{-1}$, the microstructure of aggregates was denser than the undisturbed soil, and the average particle diameter of the aggregate decreased by $2.43 \%, 3.25 \%$ and $3.55 \%$, respectively, compared with the undisturbed soil.

Aggregate breakdown was mainly caused by moderate to great rainfall intensities. The degree of fragmentation increased with the increase of raindrop diameter, rainfall intensity and rainfall energy, and more aggregate particles converted to finer particles. Consequently, these tiny particles intensified the pore clogging and infiltration weakening, exacerbated surface runoff and soil loss and reduced soil fertility; this process even accelerated the formation of surface crust and destroyed the soil structure. Therefore, to improve our understanding of the soil erosion process, synchrotron-based X-ray microcomputed tomography should be more widely used in the field of soil erosion, in combination with other methods, to study microstructure and soil aggregate fragmentation mechanisms.

\section{CONFLICT OF INTEREST}

There is no conflict of interest to declare.

\section{ORCID}

Li Guangluhttps://orcid.org/0000-0003-4107-8587

\section{REFERENCES}

Adesodun J.K., Adeyemi E.F. \& Oyegoke C.O. (2007). Distribution of nutrient elements within waterstable aggregates of two tropical agro-ecological soils under different land uses. Soil Till. Res.,92 , 190-197. https://doi: $10.1016 /$ j.still.2006.03.003

Anderson R., Kristofor R.B. \& Lisa S.W. (2019). Soil Aggregate Stability as Affected by Landuse and Soil Properties in the Lower Mississippi River Valley. Soil Sci. Soc. Am. J. ,83 ,1512-1524.https://doi: 
10.2136/sssaj2019.05.0139

Assouline S. (2004). Rainfall-Induced Soil Surface Sealing: A Critical Review of Observations, Conceptual Models, and Solutions. Vadose Zone J. 3(2) , 5 70-591. https://doi: 10.2113/3.2.570

Assouline S., \& Ben-Hur M. (2006). Effects of rainfall intensity and slope gradient on the dynamics of interrill erosion during soil surface sealing. Catena ,66(3) 211-220. https://doi: 10.1016/j.catena.2006.02.005

Bronick, C.J., \& Lal, R. (2005). Soil structure and management: a review. Geoderma , 124(1-2) , 3-22. https://doi: 10.1016/j.geoderma.2004.03.005

Chen R.C., Dreossi D., \& Mancini L. (2012). PITRE: software for phase-sensitive X-ray image processing and tomography reconstruction.J. Synchrotron Radiat ., 19(5) , 836-845. https://doi: $10.1107 /$ S0909049512029731

Dal Ferro N., Charrier P., \& Morari F. (2013). Dual-scale micro-CT assessment of soil structure in a longterm fertilization experiment. Geoderma, 204 , 84-93. https://doi: 10.1016/j.geoderma.2013.04.012

Field, D.J., Minasny, B., \& Gaggin, M. (2006). Modelling aggregate liberation and dispersion of three soil types exposed to ultrasonic agitation. Aust. J. Soil Res ., 44 , 497-502. https:// doi: 10.1071/sr05127

Fu, Y., Li, G.L., \& Zheng. T.H. (2017). Splash detachment and transport of loess aggregate fragments by raindrop action. Catena 150,154-160. https://doi: 10.1016/j.catena.2016.11.021

Fu, Y., Li, G.L., Wang, D., Zheng, T.H., \& Yang, M.X. (2019). Raindrop Energy Impact on the Distribution Characteristics of Splash Aggregates of Cultivated Dark Loessial Cores. Water , 11 , 1514. https://doi: $10.3390 /$ w11071514

Fu, Y., Li G.L., Zheng, T.H., Zhao, Y.S., \& Yang, M.X. (2020). Fragmentation of soil aggregates induced by secondary raindrop splash erosion.Catena,185,104342. https://doi: 10.1016/j.catena.2019.104342

Ghadiri, H., Hussein, J., \& Rose, C.W. (2007). A study of the interactions between salinity, soil erosion, and pollutant transport on three Queensland soils. Aust. J. Soil Res .,45(6) ,404-413. https://doi: 10.1071/SR07038

Gao, W., Steffen, Schlüter, Blaser, S.R.G.A., Shen, J., \& Vetterlein, D. (2019). A shape-based method for automatic and rapid segmentation of roots in soil from X-ray computed tomography images: Rootine.Plant E Soil ., 441(1-2) ,643-655. https://doi: 10.1007/s11104-019-04053-6

Garbout, A., Munkholm, L.J., \& Hansen, S.B. (2013). Temporal dynamics for soil aggregates determined using X-ray CT scanning.Geoderma , 204 ,15-22. https://doi: 10.1016/j.geoderma.2013.04.004

Gelaw, A.M., Singh, B.R. \& Lal, R. (2015). Organic carbon and nitrogen associated with soil aggregates and particle sizes under different land uses in Tigray, northern Ethiopia. Land Degrad. Dev ., 26 , 690-700. https://doi: 10.1002/ldr.2261

Han, Q.L., ZH, Y.D., \& Lui, L. (2019). A Simplifed Convolutional Network for Soil Pore Identifcation Based on Computed Tomography Imagery. Soil Sci. Soc. Am. J .,83 ,1309-1318. https://doi: 10.2136/sssaj2019.04.0119

Huang, R., Lan, M., \& Liu, J. (2017). Soil aggregate and organic carbon distribution at dry land soil and paddy soil: the role of different straws returning.Environmen.Sci.Pollut. Res., 24(36) ,27942-27952. https://doi: 10.1007/s11356-017-0372-9

Hu, X., Li, Z.C., Li, X.Y., \& Liu, L.Y. (2016). Quantification of soil macropores under alpine vegetation using computed tomography in the Qinghai Lake Watershed, NE Qinghai-Tibet Plateau. Geoderma ,264 , 244-251. https://doi: 10.1016/j.geoderma.2015.11.00 
Hu, F., Liu, J., Xu, C., Du, W., Yang, Z.H., Liu, X.M., Liu, G., \& Zhao, S.W. (2018). Soil internal forces contribute more than raindrop impact force to rainfall splash erosion. Geoderma , 330 , 91-98. https://doi: 10.1016/j.geoderma.2018.05.031

Jastrow J.D. (1996). Soil aggregate formatin and the accrual of particulate and mineral-associated organic matter. Soil Biol. Biochem .,28 , 665-676. https://doi: 10.1016/0038-0717(95)00159-X

Kinnell, P.I.A. (2005). Raindrop impact induced erosion processes and prediction: A review. Hydrol. Process ., 19, 2815-2844. https://doi: 10.1002/hyp.5788

Kravchenko, A., Wang, A., Smucker, A., \& Rivers, M. (2011). Long-term differences in tillage and land use affect intra-aggregate pore heterogeneity. Soil Sci. Soc. Am.J ., 75 , 1658-1666. https://doi: 10.2136/sssaj2011.0096

Lee, S.S., Gantzer, C.J., Thompson, A.L., Anderson, S.H., \& Ketcham, R.A. (2008). Using high-resolution computed tomography analysis to characterize soil-surface seals. Soil Sci. Soc. Am. J .,72(5) , 1478-1485. https://doi: 10.2136/sssaj2007.0421

Legout, C., Leguédois, S., Le Bissonnais, Y., \& Issa, O.M. (2005). Splash distance and size distributions for various soils.Geoderma , 124 , 279-292. https://doi:10.1016/j.geoderma.2004.05.006

Li, G.L., Fu, Y., Li, B.Q., Zheng, T.H., \& Wu, F.Q. (2018). Micro-characteristics of soil aggregate breakdown under raindrop action.Catena , 162 , 354-359. https://doi: 10.1016/j.catena.2017.10.027

Li Z.C., Hu, X., \& Li, X.Y. (2019). Characterization of Root Architectures and Soil Macropore Networks Under Different Ecosystems Using X-ray CT Scanning in the Qinghai Lake Watershed, NE Qinghai - Tibet Plateau. J. Soil Sci.Plant Nutr.,19, 743-757. https://doi: 10.1007/s42729-019-00074-3

Luo, L., Lin, H., \& Li, S. (2010). Quantification of 3-D soil macropore networks in different soil types and land uses using computed tomography. Journal of Hydrology (Amsterdam) , 393(1-2),53-64. https://doi: 10.1016/j.jhydrol.2010.03.031

Mahmoodabadi, M., Ghadiri, H., Bofu, Y., \& Rose, C. (2104). Morphodynamic quantification of flowdriven rill erosion parameters based on physical principles. J. Hydrol ., 514 , 328-336. https://doi: 10.1016/j.jhydrol.2014.04.041

Ma, R., Cai, C.F., Li, Z.X., Wang, J.G., \& Xiao, T.Q. (2015). Evaluation of soil aggregate microstructure and stability under wetting and drying cycles in two Ultisols using synchrotron-based X-ray micro-computed tomography. Soil \& Tillage Research, 149 ,1-11. https://doi: 10.1016/j.still.2014.12.016

Munkholm, L.J., Heck, R.J., \& Deen, B. (2012). Soil pore characteristics assessed from X-ray micro-CT derived images and correlations to soil friability. Geoderma , 181 ,22-29. https://doi: 10.1016/j.geoderma.2012.02.024

Pagliai, M., Vignozzi, N., \& Pellegrini, S. (2004). Soil structure and the effect of management practices. Soil Tillage Res .,79(2),131-143. https://doi: 10.1016/j.still.2004.07.002

Perret, J.S., Prasher, S.O., \& Kacimov, A.R. (2003). Mass fractal dimension of soil macropores using computed tomography: from the box-counting to the cubecounting algorithm. Eur. J. Soil Sci .,54, 569-579. https://doi: 10.1046/j.1365-2389.2003.00546.x

Peth, S., Horn, R., Beckmann F, Donath, T., Fischer, J., \& Smucker, A.J.M. (2008). Three-Dimensional Quantification of Intra-Aggregate Pore-Space Features using Synchrotron-Radiation-Based Microtomography. Soil Sci. Soc. Am. J. , 72(4),897-907. https://doi: 10.2136/sssaj2007.0130

Pirmoradian, N., Sepaskhah, A.R., \& Hajabbasi, M.A. (2005). Application of fractal theory to quantify soil aggregate stability as influenced by tillage treatments. Biosyst Eng. , 90 ,227-234. https://doi: 10.1016/j.biosystemseng.2004.11.002 
Ramos, M.C., Nacci, S., \& Pla, I. (2003). Effect of raindrop impact and its relationship with aggregate stability to different disaggregation forces. Catena , 53 , 365-376. https://doi: 10.1016/S0341-8162(03)000869

Robinson, D.A., \& Phillips, C.P. (2001). Crust development in relation to vegetation and agricultural practice on erosion susceptible, dispersive clay soils from central and southern Italy. Soil Tillage Res ., 60 , 1-9. https://doi: 10.1016/s0167-1987(01)00166-0

Sajjadi, A.S., \& Mahmoodabadi, M. (2015). Aggregate breakdown and surface seal development influenced by rain intensity, slope gradient and soil particle size. Solid Earth , 6 , 311-321. https://doi:10.5194/se-6$311-2015$

Slattery, M.C., \& Burt, T.P. (1997). Particle size characteristics of suspended sediment in hillslope runoff and stream flow. Earth Surf. Proc. Land ., 22 , 705-719. https://doi: 10.1002/(sici)10969837(199708)22:8<705::aid-esp739>3.0.co;2-6

Six, J., Paustian, K., Elliott, E.T., \& Combrink, C. (2000). Soil structure and organic matter: 1. Distribution of aggregate-size classes ad aggregate-associated carbon. Soil Sci. Soc. Am. J .,64,681-689. https://doi:10.2136/sssaj2000.642681x

Shi, Z.H., Yan, F.L., Li, L., Li, Z.X., \& Cai, C.F. (2010). Interrill erosion from disturbed and undisturbed samples in relation to topsoil aggregate stability in red soils from subtropical China. Catena, 81 ,240-248. https://doi: 10.1016/j.catena.2010.04.007

Taina, I.A., Heck, R.J., \& Elliot, T.R. (2008). Application of X-ray computed tomography to soil science: A literature review. Canadian Journal of Soil Science . 88(1) ,1-19. https://doi: 10.4141/CJSS06027

Wang, X., Cammeraat, Erik L.H., Cerli, C., \& Kalbitz, K. (2014). Soil aggregation and the stabilization of organic carbon as affected by erosion and deposition. Soil Biol Biochem ., 72,55-65. https://doi: 10.1016/j.soilbio.2014.01.018

Wang, A., Yan, X., \& Wei, Z. (2018). ImagePy: an open-source, Python-based and platform-independent software package for bioimage analysis. Bioinformatics,34, 3238-3240. https://doi: 10.1093/bioinformatics/bty313

Wick, A.F., Daniels, W. L., Nash, W.L., \& Burger, J.A. (2016). Aggregate recovery in reclaimed coal mine soils of SW Virginia. Land Degrad. Dev. , 27 ,965-972. https://doi:10.1002/ldr.2309

Xiao, H., Liu, G., Abd-Elbasit, M.A.M., \& Zhang, X.C. (2017). Effects of slaking and mechanical breakdown on disaggregation and splash erosion. Eur. J. Soil Sci .. 68, 797-805. https://doi: 10.1111/ejss.12482

Zhao, D., Xu, M.X., \& Liu, G.B. (2017). Effect of vegetation type on microstructure of soil aggregates on the Loess Plateau, China.Agr. Ecosyst. Environ ., 242 ,1-8. https://doi: 10.1016/j.agee.2017.03.014

Zhou, H., Peng, X., Peth, S., \& Xiao, T.Q. (2012). Effects of vegetation restoration on soil aggregate microstructure quantified with synchrotron-based micro-computed tomography. Soil Till. Res .,124 ,17-23. https://doi: 10.1016/j.still.2012.04.006

\section{Hosted file}

Table1.docx available at https://authorea.com/users/343126/articles/469784-impact-ofraindrop-sizes-and-intensities-on-the-microcharacteristics-of-soil-aggregates

\section{Hosted file}

Table2.docx available at https://authorea.com/users/343126/articles/469784-impact-ofraindrop-sizes-and-intensities-on-the-microcharacteristics-of-soil-aggregates

\section{Hosted file}


Table3.docx available at https://authorea.com/users/343126/articles/469784-impact-ofraindrop-sizes-and-intensities-on-the-microcharacteristics-of-soil-aggregates

\section{Hosted file}

FIGURE 1.docx available at https://authorea.com/users/343126/articles/469784-impact-ofraindrop-sizes-and-intensities-on-the-microcharacteristics-of-soil-aggregates

\section{Hosted file}

FIGURE 2.docx available at https://authorea.com/users/343126/articles/469784-impact-ofraindrop-sizes-and-intensities-on-the-microcharacteristics-of-soil-aggregates

\section{Hosted file}

FIGURE 3.docx available at https://authorea.com/users/343126/articles/469784-impact-ofraindrop-sizes-and-intensities-on-the-microcharacteristics-of-soil-aggregates

\section{Hosted file}

FIGURE 4.docx available at https://authorea.com/users/343126/articles/469784-impact-ofraindrop-sizes-and-intensities-on-the-microcharacteristics-of-soil-aggregates 